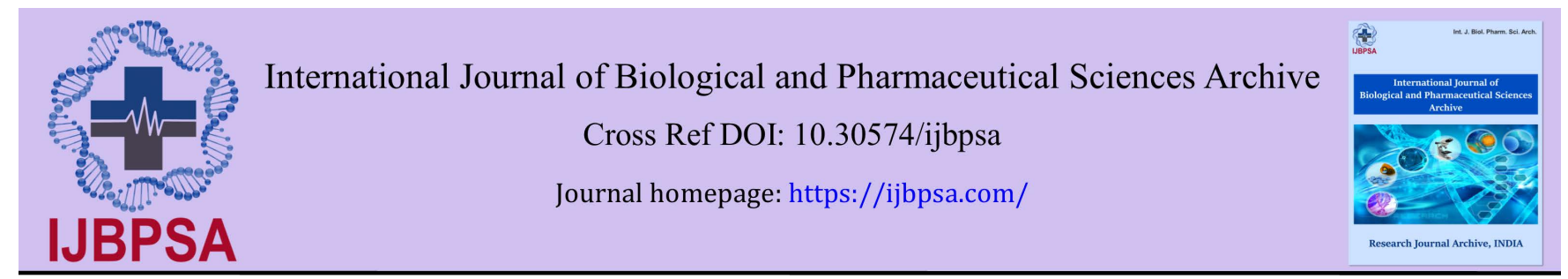

(REVIEW ARTICLE)

\title{
Inflammatory reaction - A posit to the double-edged sword
}

\author{
Chukwuedozie Francis Nwachukwu* \\ Department of Biochemistry and Forensic Science, Faculty of Science, Nigeria police Academy, Nigeria.
}

International Journal of Biological and Pharmaceutical Sciences Archive, 2021, 01(02), 197-209

Publication history: Received on 05 April 2021; revised on 14 May 2021; accepted on 17 May 2021.

Article DOI: https://doi.org/10.30574/ijbpsa.2021.1.2.0036

\begin{abstract}
Response by inflammation is triggered by arrays of causes, which include disrupted cells, toxins, germs, and others. It underlies a wide variety of pathophysiological changes. Many aspects of inflammation as it relates to the pathology of various inflammations are very much understood. Yet the healthy roles of inflammation are widely unknown. Inflammation has a controversial role in health and its meanings are, a matter of viewpoint. It has critical roles in protecting organisms from pathogens and injurious substances likewise causing a driving variety of disease progression. On this ground the research aimed at prescribing the essential needs for effective regulations of inflammatory responses. Efficient control of the inflammatory process will avert a plethora of diseases. Articles used for this review were obtained using appropriate keywords on six electronic databases including nature, advantage, disadvantage, and immune response regarding inflammation and immunological response. Inflammation is selfperpetuating though no disease is caused by inflammation as it is not self-triggering. Additionally, the research did weigh up the merits alongside the demerit of inflammation to advocate for effective regulation of inflammation. Essentially, inflammation is a required mechanism in healthy and unhealthy status in humans hence there is a need for importunate reconsideration, exploring its therapeutic benefits.
\end{abstract}

Keywords: Inflammation; Disease; Regulation; Double-edge; Self-perpetuating

\section{Introduction}

Inflammation, a biological response to homeostatic perturbation [1], involves vascular and cellular components with diversities of clinical signs, which presents swelling, redness, heat, pain and functional impairment [2, 3]. The disease expression of the inflammation is centered on the imbalance of these five cardinal signs. This response is triggered by altered tissue in any form of injury. Fundamentally inflammation is tissue-damaging which progresses through the involvements of fluid, plasma proteins, and leucocyte to the inflamed cells [4]. The movement is aided by changes in the local vasculature and caused the vasodilation, in addition to intensified permeability in the vascular cells. All these give rise to much blood flow to the site [5]. The release of cytokines, noticeable alter in the number of leucocyte cells is the main feature of inflammation [6,7]. This pervasive phenomenon operating during severe perturbations of homeostasis [8], is broadly characterized by nonspecific response to tissue malfunctioning so as to combat the disrupted cells. This multifarious biological response involves the interplay of biochemical molecules and is targeted at, protecting tissue from damage [2]. Effective regulation of response to inflammatory will reduce the severity due to inflammatory damage and the necessary homeostasis will be achieved.

The Inflammatory process is a normal, natural response by immunity. However, lingering inflammation destroys and may be linked with autoimmune ill-health. Research shows that hiked-in inflammation is the key force causing inflammation disease progression that results in organ disease $[9,10]$. Chronic inflammation associates with rising and increase of various diseases [11].

\footnotetext{
${ }^{*}$ Corresponding author: Nwachukwu Francis Chukwuedozie

Nigeria police Academy, Department of Biochemistry and Forensic Science, Faculty of Science, Imo State University, Owerri.
} 
Failure to efficiently control the inflammatory process results undesirable outcome [12], hence the inflammatory reactions should be restricted to healing. Considering the vast array of disease of which prolong inflammation may precipitate and drive-cancer, stroke, diabetes, cardiovascular disease, gum disease, nephritis, bowel inflammatory disease, rheumatoid arthritis, lupus and polymyalgia rheumatic $[13,14,15,16]$. Therefore, it is thoughtful to have a controlled inflammatory reaction rather that spontaneous reaction to injury. In contemporary 'revelations', chronic inflammation is factored in worsening conditions of diseases functions loss, among others (Fig. 2). Some literatures have considered the demerits of inflammation as unparalleled amid physiologic processes while others viewed it as necessity for the continuation of life process. Then inflammation has puzzling roles in health.

Of course, inflammation is not without merits. The acute form of inflammation can defend and heal of the body of disease. This acute inflammation is an amazing process, necessary for good health. The research work aims on the need to regulate inflammation, the knowledge of inflammation. The specific objectives were to advance for efficient regulation of inflammation using current issues on nature, advantages and disadvantages of inflammation.

\subsection{Concept statement on inflammation}

Inflammation is not self-triggered but self-perpetuating, having the capabilities of bittersweet connection and is highly a conserved process that appear crucial in defending organisms in the event of threat to organism. The living organisms engages inflammation as its initial defense process. Clearly, it is certain that we are aware of the inflammatory processes for futuristic modalities in treatment various health issues. Health caregivers should have fundamental knowledges on nature of cellular inflammation processes.

\subsection{Nature of inflammation}

Inflammation, a primary component of the process on the protection of the host on infection, injury, and wounds [17], is elicited by stimulus perceived as a threat to tissue homeostasis [18]. To counteract the insult eliciting threat, immunity dispatches series of events that open up in several stages [19]. Firstly, resident cells in the tissue of the innate immune system will alarm neutrophils in circulation, preceding the detection of the damaging insult. The movement to the perturb tissue at the site of the inflamed cells, will advance the draft of monocytes and increase the effectiveness of proinflammatory environment, promoting appropriate interaction at inflamed cell. In a particularly appropriate situation, apoptosis by neutrophils occurs after performing the required task at the site of inflammation, and subsequently, these apoptotic neutrophils are engulfed by macrophages. Removal of apoptotic neutrophils will promote a switch from proinflammatory to an anti-inflammatory cell phenotype [20], this is a basic required for macrophage exit through the lymphatic vessels favoring restoration of homeostasis of tissue.

The decisive stage in the concept is that resolution is a vigorous process with the desire to energetically suppress and end vigorous reaction of inflammation once its desired aim is attained. It is designated by five cardinal signs [21]: redness (resulting from increase flow of blood to the site of the inflamed area), swelling (resulting due to chemicals that cause blood vessels to leak protein-rich fluid into the tissues), heat (resulting from increase flow of blood alongside prostaglandin $\mathrm{E}_{2}$ increase in the amount in the brain), pain (a defense mechanism to alert the body to move away from the site) and Loss of function ('Rigor', tissue destruction, pyrogen or dehydration). The imbalances of these signs are factored in the development of diseases. The components of inflammation are depicted by inflammatory triggers; the sensors; mediators and the effector tissues that are affected. The nature and extend of responses to inflammation are reliant on the feature of the inducer (parasite and others) and its perseverance [22]. A distinctive feature of inflammatory response is that harm to self cannot be avoided [8].

This all-purpose aggressive defense response (inflammation) towards disrupted tissue is used by immune systems [23], to combat interlopers [8]. Self-healing and disease progression in many metabolic diseases have inflammatory connotations [24]. Metabolic diseases are the drawback and are due to the self-perpetuating and the nonspecific nature of the inflammatory response to tissue injury. The researcher's train of thought presents inflammations as a natural, normal physiological response by the immune system to injury or infection. The researcher considers effective regulation of inflammation as a positive triumph for the body, inflammation is crucial in immunologic responses needs to be adjusted for a satisfactory outcome.

According to Noah et al. [8] and Medzhitov [1], microscopic organisms, physical and chemical agents, unfitting responses of immune cells, and dead tissues are among listed several factors that can stimulate and initiate inflammation. The responses are an initial effort to stop the damaging effect of the trigger on the normal function of the tissue [25]. The researchers perceived inflammation, as not a disease in itself but may have links to several diseases because it is the response to situations perceived as injurious to the body. 
The primary nature of inflammation targets the primary inducer and vigorously removes the cause of the insult with the subsequent homeostatic restoration of tissue functions [1, 19]. As mentioned previously, the self-perpetuating nature of inflammation may depict the innocuous and malicious mischief in its perception. Extrapolating inflammatory reactions from literature searched, the double-edged nature of inflammation, stems from its self-perpetuating nature and non-direction response. Understanding the inflammatory cascade (Fig. 1) on how inflammation is initiated, perpetuated among others, coupled with the detailed inflammatory mechanism, will advance a better way to control inflammation. This will result in a positive impact on health.

The acute/self-resolving or chronic/non-resolving type of inflammation [26], (Fig. 3), involves the permeability of vascular membranes, aggressive exodus of blood components out and into the inflamed tissues [27]. Inflammation of acute type, lasting for a short period of reaction will mostly promote remedial of tissue malfunctioning: the infiltration of leukocytes to the injured site will get rid of the stimuli, and reparation of the tissue follows. Conversely, inflammation of chronic type is a long-term, uncontrolled and unfavorable response that engages vigorous inflammation, tissue damage, and efforts to repair tissue. This tenacious response of inflammation (Fig. 4) is linked to a plethora of lifedebilitating conditions and its disease attendance, which are exemplified as allergic reaction, atherosclerotic conditions, cancer disease, and arthritis diseases, autoimmune disorders among others.

Generally, inflammatory phenomenon serving well-desired effect, could promote good outcome. Notwithstanding, issues may come up if the inflammatory reactions did halt, rather perpetuate and transformed to the chronic stage, will invariably affect negatively the health conditions in the body. Despite huge advances towards the knowledge in understanding the actual processes underlying inflammation, much has not been known of the role inflammation plays in regulating health.

Inflammation, when regulated properly, is theoretically useful in addressing different health situations. The exertion is anchored on the fact that there are higher serious chances of severe disease due to infections in individuals' deficient in the gene of primary components of inflammation, like neutropenia-a very small amount of neutrophils. Studies in a genetic defect in the genes that encode for proinflammatory cytokines and promotor of inflammation using mouse knock-out showed features of hyper susceptibility to infection [28]. However, substances that reduce inflammation may be beneficial. Cytokine (IL-10), having anti-inflammatory potentials, has a key role in limiting the immunological reactions pathogens and hence averting destructions to the cells of the host organism [29]. Of late, literature has reviewed that IL-10 and related cytokines can hasten the process of healing of tissue in damage due to inflammatory reaction [30].

The ability to logically control inflammation is regarded as the basis for its therapeutic value as distinct from mere reducing inflammation-which is in common practices.

\subsection{Advantages of inflammation}

From evolutionary advantage, some of the players of inflammatory cascade (phagocytosis and chemotaxis), used by lower organisms, later were co-opted as a defensive protocol in maintaining the integrity of higher organisms [31]. As several analysts have noted, the inflammatory system is crucial for survival [32]. It alarms the body's defensive mechanism of the existence of infection, hence putting the leucocyte into action. This results in a fast clearance infection [33]. Under a healthy situation, immunity has the potential to fight a sizable volume of pathogens, with favorable levels of inflammatory responses in clearing the infections from the affected host tissue. Resolution of inflammation happens very quickly under minimal destruction of the host. This is dependent on the tight control of cytokines. In the initiation of inflammation reactions, cytokines are paramount likewise hiking immune response.

Newer researches are providing, convincing shred of evidences on the healing power of inflammatory response to muscle tissue injury. A favorable amount of inflammation could initiate quality reparation of injury [34]. In this train of thought, Mikkelsen et al. [35] And Nunes-Silva [36], demonstrated that medicine to keep inflammation at check is able to blunt muscle growth if given in high doses.

In the furtherance of excess anti-inflammatory medication such as cortisone, studies have shown that, it slows wound healing [37]. This study is interrelated to the reason insulin-like growth factor and inflammatory cell components help the healing of wounds $[38,39]$. In addition, factors (deficiency of leukocyte) that decrease the capacity for inflammatory defense will subsequently cause vulnerability to infection. Literature searched have shown that inflammation actually helps to heal damaged muscles [40]. 
Reducing inflammation through ice-cold water treatment among the sportspeople is no longer in invoke. Researches have shown that training adaptation using cold water treatment lowered proliferation of satellite cell [35]. Prolong effects results in reduce muscular enlargement and complexity of cell muscle fibers structure [41]. On the basis of conventional wisdom, inflammation may be adapted to suit the challenges in health.

Inflammation as previously mentioned in tissue reparation due to infection or otherwise malfunctioning tissue, sometimes seen as crucial parts of the regeneration of tissue and destruction of microbes [42], detoxification of toxins, clearing of infections [43], healing process and repair of damaged tissue [44]. This may be turning conventional wisdom on its head necessitating that inflammation must be largely controlled to encourage healing. The idea in these findings may suggest that existing and future therapies used to combat inflammation should be closely examined to ensure that the benefits of inflammation are not eliminated.

On the other hand, many relevant genes of immune disruption can give rise to unrestrained inflammation, showing that inflammation is rapidly repressed by gene regulating the productions of pro-inflammatory proteins so as to up-hold health when the stimuli of the inflammation are no longer their [18]. In the absence of efficient regulation, a disproportionate inflammatory response could have destructive effects, with resultant unintended harm.

Inflammation among other responses in the body must be efficient [45] through effective regulation [46]. The therapy here will be to control inflammation in order to achieve desired results and prevent lingering. If this agent cause of the inflammatory response is unremoved, or rather there is an obstruction in the repairing mechanism, the inflammation might result in an undesirable stage. Research justification hinges on how we can subtly alter inflammation at a later time point to explore the advantages of inflammation.

\subsection{Disadvantages of inflammation}

The compulsive character of aged tissues and most importantly in all age-related ill-health is severe inflammation. During aging, the body is weak in the resolution of inflammation. Licastro et al. [47] reported increased proinflammatory response with age. An increase in plasma level of IL-6 is associated with aging and IL-6 positively correlates with inflammation [48]. The mechanism is complicated and versatile [49]. Though humans are prone to more inflammations as we age, naturally the body has agents that modulate inflammation such as Nitric Oxide [50]. The worst case is those who are obese [51] because of the increased levels of pro-inflammation cytokines.

The development of inflammation unintended harm might rely on the inefficiency of host defense capability, late stimulation of adaptive immune system alongside poor specificity of the innate immune system [52]. That being said, there are conditions that cause exaggerated or abnormal inflammatory responses, some are exogenous while others are endogenous. It will not be very correct to assume that mortality due to infection is exclusively a result of pathogenic microbial exploitation. Although most of the literature searched showed collateral evidence suggesting mortality of host from the pathogen is most time rely on the level of unintended harm triggered by the inflammatory response from the host $[53,54]$. Inflammation from the host is of paramount contribution to the pathology of the disease and in most instances, the harm from self-damage is more than that inflicted by the microbial pathogen [54].

Most neuronal destruction caused by bacterial meningitis and cerebral malaria is attributed to wild inflammation reactions [55]. Moreover a high amount of injury which happens from the trauma of brain injury comes from inflammatory responses rather than from direct mechanical damage. Furtherance to this, it is suggestive that brain inflammation preceding trauma is destructive rather than favorable. Traumatic injuries on the central nervous system are mostly fatal in humans and likewise, other species, in the absence of improved medical intervention [56]. However, peripheral tissues, injury to the central nervous system can cause irreparable damage because of limited regenerative potentials [56].

Previous works have shown that the inflammatory response has a key role in atherosclerosis development [57]. This formerly known bland lipid storage disease (atherosclerosis), actually has an ongoing inflammatory response undertone. Modern improvement through basic science has proven a basic role of an inflammatory process in facilitating each of the stages of this disease from beginning to progression and the thrombotic complications of atherosclerosis [58]. Mounting experimental evidence strongly supports the role of inflammatory mechanisms among others, in many facets of vascular disease [59]. Again, research has revealed the specific function of inflammation in disease like Alzheimer's disease [60], it facilitates serious and life-threatening complications in stroke patients [61] and a host of others. 
Table 1 A case in points of inflammation contributing to pathogenesis in human disease

\begin{tabular}{|c|c|}
\hline Disease & Mechanism \\
\hline Allergy & $\begin{array}{l}\text { Hypersensitivity of the immune system to typically harmless substances in the } \\
\text { environment. }\end{array}$ \\
\hline Alzheimer's disease & Brain cell inflammation, causing destruction of the tissues of brain. \\
\hline Anaemia & Cytokines storm on erythropoietin production due to inflammation \\
\hline Ankylosing spondylitis & Autoimmune reactions against joint surfaces due to inflammatory cytokines. \\
\hline Asthmatic disease & Autoimmune reactions induced by cytokines against airway lining. \\
\hline Autism & $\begin{array}{l}\text { Autoimmune reactions due to inflammatory cytokines in the brain causing } \\
\text { seizure of right hemisphere development }\end{array}$ \\
\hline Arthritis & Destruction of joint cartilage and synovial fluid due to inflammatory cytokines. \\
\hline Carpal Tunnel Syndrome & $\begin{array}{l}\text { Chronic inflammation induced excessive muscle tension shortening tendons in } \\
\text { the forearm and wrist compressing the nerves }\end{array}$ \\
\hline Celiac & Severe immune mediated damages in the intestinal lining due to inflammation. \\
\hline Congestive heart failure & Heart muscle wasting due to chronic inflammation. \\
\hline Eczema & $\begin{array}{l}\text { Chronic inflammation of the gut and liver with poor detoxification and often } \\
\text { antibodies against Transglutaminase- } 3 \text {. }\end{array}$ \\
\hline Fibromyalgia & $\begin{array}{l}\text { Inflamed connective tissue often food allergy related and exacerbated by } \\
\text { secondary nutritional and neurological imbalances. }\end{array}$ \\
\hline Fibrosis & Traumatized tissue due to inflammatory cytokines attack \\
\hline Gall Bladder Disease & $\begin{array}{l}\text { Swelling of the bile duct or excess cholesterol produced in reaction to gut } \\
\text { inflammation. }\end{array}$ \\
\hline GERD & $\begin{array}{l}\text { Inflammation of the oesophagus and digestive tract nearly always food } \\
\text { sensitivity and } \mathrm{pH} \text { driven due to inflammation. }\end{array}$ \\
\hline Guillain-Barre & $\begin{array}{l}\text { Nervous system autoimmune attack often triggered by autoimmune response } \\
\text { to external stressors such as vaccinations. }\end{array}$ \\
\hline Hashimoto's Thyroiditis & $\begin{array}{l}\text { Antibodies triggered autoimmune attack against thyroid enzymes and proteins, } \\
\text { originating from the gut. }\end{array}$ \\
\hline $\begin{array}{l}\text { Toxic Shock } \\
\text { Syndrome/Scarlet Fever }\end{array}$ & Extreme inflammation Cytokine storm Oxidative damage \\
\hline Kidney failure & $\begin{array}{l}\text { Damage nephrons and tubules in the kidneys due to inflammatory cytokines } \\
\text { which are restricted in circulation. }\end{array}$ \\
\hline Lupus & Autoimmune attack against connective tissue due to inflammatory cytokines. \\
\hline Multiple Sclerosis & Autoimmune reactions against myelin due to inflammatory cytokines. \\
\hline Neuropathy & $\begin{array}{l}\text { Autoimmune reactions against myelin and vascular and connective tissues due } \\
\text { to inflammatory cytokines which irritate nerves. }\end{array}$ \\
\hline Pancreatitis & Pancreatic cell injury due to inflammatory cytokines. \\
\hline Psoriasis & Severe inflammation of the gut and liver with poor detoxification \\
\hline Polymyalgia Rheumatica & $\begin{array}{l}\text { Autoimmune reactions against muscles and connective tissue due to } \\
\text { inflammatory cytokines. }\end{array}$ \\
\hline
\end{tabular}

Source: Adapted with modified from Margolis and Levin [53].

In a special situation, a good number of intracellular pathogens have adapted to reproduce inside immune cells. In the course inflammation process, cells of the immune system are employed and channeled to the infection site, which 
accidentally spread with more transmission and spread of the pathogen [52]. Recent literature is suggestive of the inflammatory response of acute type as an enhancer in horizontal gene transfer among commensal and pathogenic flora in the gut which may encourage development and transmission of the antibiotic-resistant and virulence genes [61]. Unnecessary inflammation directs to expensive unintended harm, especially when unrestrained, may result in untold consequential pathology (Fig. 4).

From Table 1, it is arguable to note that in the absence of inflammatory process, the majority of diseases would be in nonexistence. The number of diseases with the mechanism showcases the relationship, inflammations have on diseases. This is why inflammation must be addressed.

Acute inflammatory process mighty be the led in the progress of the destruction of tissue following stimulus of harmful origin (e.g. bacteria) and it possibly can reduce the survival potentials rates of the organism. Furthermore, inflammation of chronic type has the capability of causing a plethora of diseases (Table 1). Hence inflammation is a normal tightly regulated mechanism of living things, failure in the regulation of inflammation will disturb the homeostatic conditions of the body. The attendant consequences range from subtle subclinical to serious life threatening-diseases (Table 1)

However, sometimes inflammation can cause further inflammation, in this process, becomes self-perpetuating and more inflammations are created in response to the existing inflammation. During the robust inflammatory reaction, there is the possibility of DNA repair machinery and cell-cycle checkpoints being halted [62], which may result in an increased mutation rate [62]. It is now known high-level inflammation contributes to cancer development $[63,64,65]$. In many human tumors, Infection-driven inflammation is the blame for the pathogenesis of many of these disease types.

The idea that the immune response drives the inflammation in the disease process is understood and that inflammatory reaction is part of the immunity that could be stimulated by any trigger has the capability to disturb tissue homeostasis [18]. Globally, coronary artery disease is the lead cause of mortality, and a major predisposition to the disease is inflammation as they have variants of genes that associate with inflammation. Though without inflammatory response, being present in the body, there might not be the presence of strokes, diabetes, cardiovascular diseases, and endless count of diseases, the catchphrase is 'controlled inflammatory'.

Inflammation is very important for normal repair processes to occur. The unregulated wild inflammation response type is unrequired and needless inflammation.

\section{Mechanism of inflammation and probable therapeutic points.}

The Inflammatory mechanism is a series of ordered, active, and changing reactions. It includes cellular and vascular events alongside specific secretions of hormones (Fig. 2).

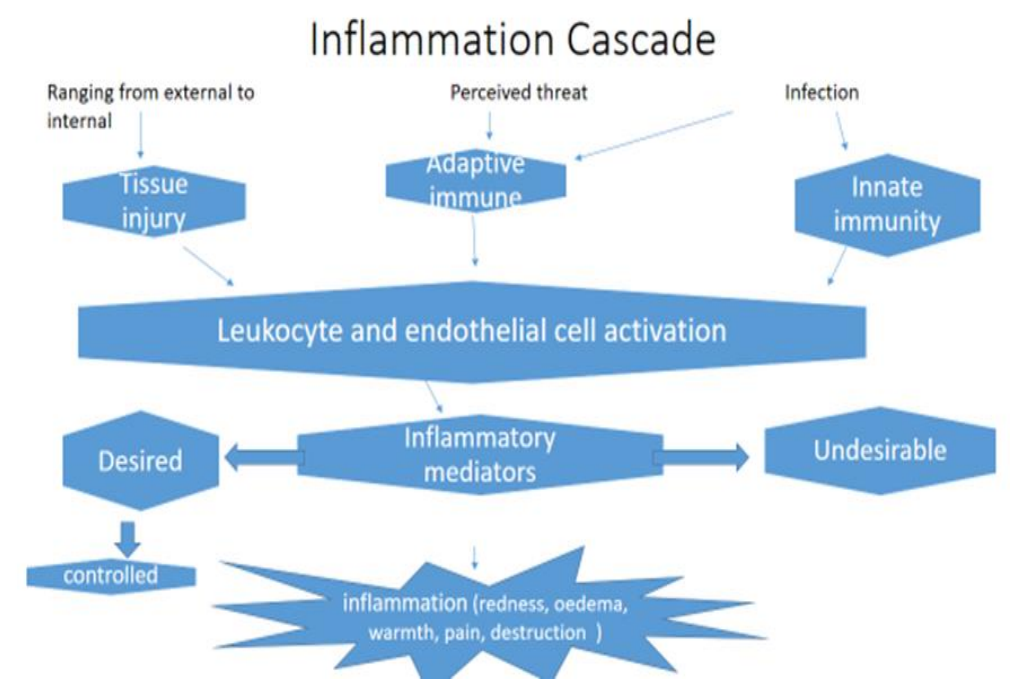

Figure 1 Simplified nature of inflammatory cascade 
Vasodilation (expansion), exudation (oedema), emigration of cells, chemotaxis, and phagocytosis define the mechanism of inflammation. Inflammatory responses from inappropriate stimulation are the primary cause of several known medical conditions (Fig. 3 and Fig. 4). The main fundamental basic feature of inflammatory response is an increase in the temperature of the host, alongside loss in function (Fig. 1) and physical change in location of cells (leukocytes, monocytes, basophils, eosinophils, and neutrophils), plasma exodus to the site of inflammation [66].

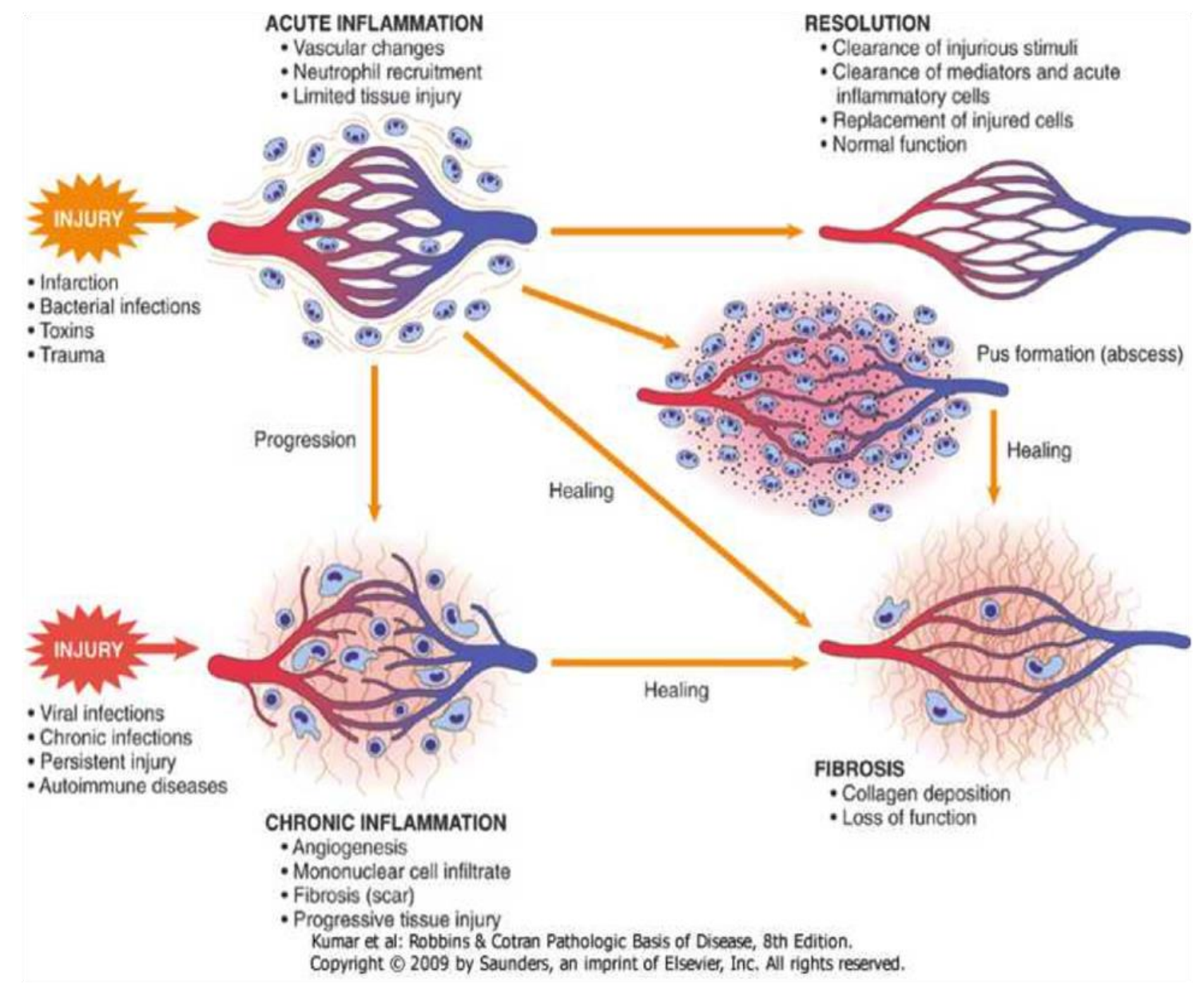

Figure 2 Morphologic patterns of inflammation source

Source: https://d1yboe6750e2cu.cloudfront.net/i/f439f61622223489ea9b13b3ec3a56ff58d8705e

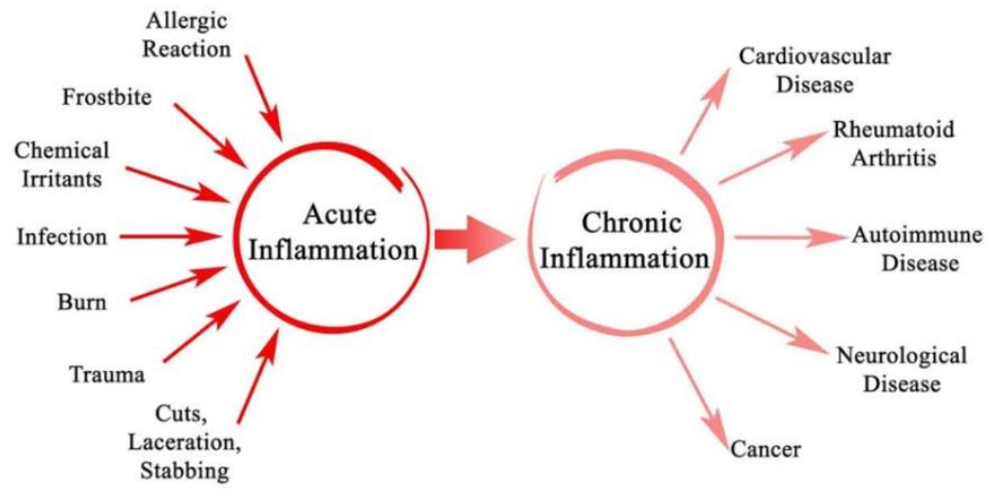

Figure 3 Inflammation becoming harmful in chronic inflammation

Source: https://www.nmamilife.com/a-z-health/chronic-v-s-acute-inflammation-know-the-difference/ 


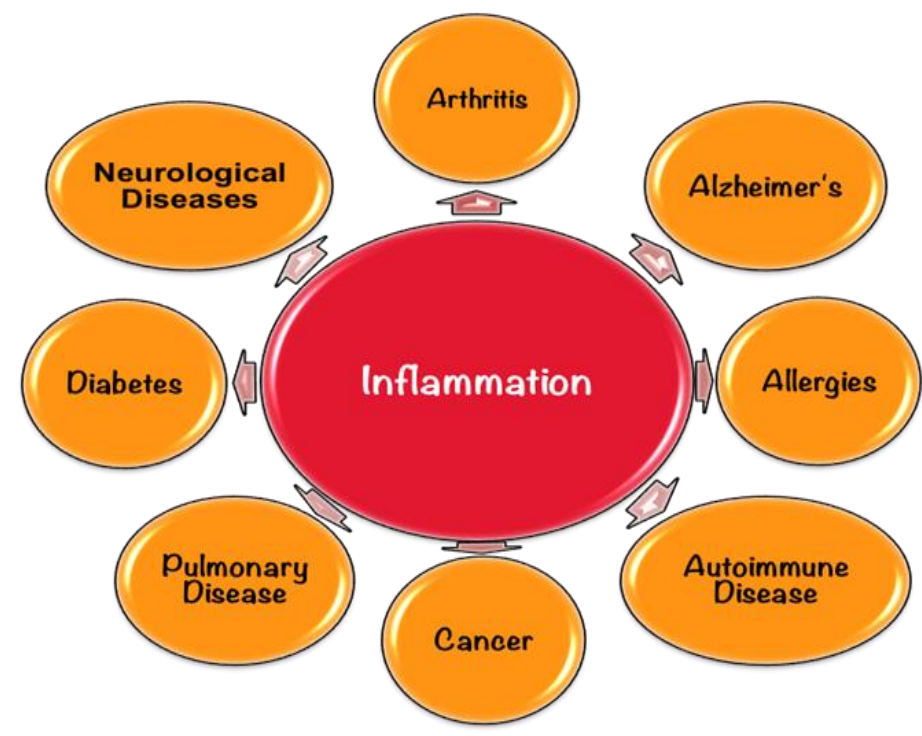

Figure 4 Inflammation at the root of most diseases

Source: https://images.app.goo.gl/7APFD77XmXfmZ9BW8

https://www.quora.com/If-inflammation-is-a-part-of-healing-why-do-we-try-to-stop-it-with-anti-inflammatory-drugs

Following the presence of inflammogen (allergens, Pathogens, toxins, frostbite, and burns) (Fig. 1 and Fig. 2), the resident immune cells (dendritic cells, macrophages, histiocytic, mast cells, and Kupffer cells) already present in tissue involved will initiate the inflammatory process. The cells are surface receptors known as pattern recognition receptors (PRRs) are capable of recognizing and binding molecules of two subclass: damage-associated molecular patterns (DAMPs). And pathogen-associated molecular patterns (PAMPs) [32, 67]. At the start of a burnt, infection, injuries, and other inflammogens, the cells are activated (PAMP or DAMP is been recognized by the PRRs) which follows the secretion mediators of inflammation that gives rise to inflammatory clinical signs (Fig. 1) [68].

The inflammatory response at the inflamed site is depicted through the initial rise the flow of blood towards the site of the injury due to an increase in vascular permeability [69] and the coordinated directional migration, with the careful build-up of various effector cells from the peripheral blood flow at the place of injury. The vasodilation, increase in blood flow and permeability of vessels, characterized the redness (rubor) and increased heat (calor) at the inflamed cell (Fig. 1). This vascular change (Fig. 2) will increase the permeability of the blood vessels, resulting in exudation (leakage) of plasma proteins (such as fibrin and immunoglobulins (antibodies), into inflamed tissue) and fluid into the inflamed tissue. These manifest as swelling (tumor) [70]. The increased tissue fluid would lead to an increase in lymphatic drainage. This will help to remove the damaging substance.

Among the released mediators like bradykinin would hike the feeling of pain (hyperalgesia). The molecules of the mediator, additionally change the blood vessels to allow the movement of cells, mainly macrophages, and neutrophils, (Fig. 2) out of the vessels of blood (extravasation) into the tissue. This moved tissue fluid has various antimicrobial mediators coming from the plasma. It includes antibodies, complement, and lysozyme that would promptly handle the inflammogens (Fig 1 and Fig 2). Proportions of the exuded tissue fluid are channeled to lymphatics regional lymph nodes, clearing microbes. The neutrophils exodus following chemotactic gradient pattern as created through the local cells to reach the injurious site. The functional loss called functio laesa, is presumably from neurological reflex in pain response. The migration of granulocytes to the inflammatory site will cause the neutralization and removal of inflammogen [2].

Cell-derived mediators alongside, many acellular biochemical events consisting of preformed plasma proteins work in parallel to start and propagate inflammation. They are the complement system activated by the coagulation and fibrinolysis systems activated by necrosis (a burn or a trauma) and bacteria [71]. After removal of inflammogen, resolution of inflammation is followed by the eventual return of tissue mononuclear cell members to the basal levels [72] (Fig 1 and Fig. 2). In this case, the reaction is acute and is constrained to the area of damaged tissue [73]. In some situations of acute inflammation, the quick employment of granulocytes (eosinophils, neutrophils, and basophils) towards the inflammation area may last longer without resolution. This unresolved inflammation (acute) may transform to chronic, thereby leading to many different types of chronic inflammatory diseases [74]. Atherosclerosis is 
an example of a chronic disease that involves inflammatory mechanisms. Atherosclerosis, identified as a lipid-driven inflammatory disease is characterized by continuous immune activation [74] and unresolved inflammation [75].

Heightened inflammation may advance plaque rupture, causing ischemic disease [76, 77]. This inflammation of the vascular wall is the onset of atherogenic events and it involves lipoprotein accumulation, Tumor Necrosis Factor (TNF) $\alpha$ and leukocyte recruitment (especially monocytes and macrophages), and expression of proinflammatory cytokines, such as interleukin (IL)-1 $\beta[58,76]$. Failure to resolve this inflammatory response is the drive-in arteriosclerosis and beyond. Atherosclerosis underpins the pathological nature associated with many cardiovascular diseases, including but not limited to coronary artery disease, stroke, ischemic gangrene, and myocardial infarction [76]. Inflammatory markers may be predictive and associated with the causes, together with the consequences of the aforementioned inflammatory diseases [78].

Inflammation could potentially be halted by actively turning on/promoting a functional and effective resolution of a phenomenon [75] using a therapeutic approach to avert progress beyond arteriosclerosis. Additionally, proteases in inflammatory exudates [79] have roles in the inflammation response [80]. Proteolytic activities of these enzymes are vital therapeutic points for the regulation inflammation responses [81].

\section{Conclusion}

In the past, the only accepted treatment was medications that reduce Inflammation. At the moment these prescriptions are no longer scientifically or morally defensible. The discovery, a few years ago that inflammation is crucial for the life process is slowly leading to a radical change in how inflammation is viewed. The obvious roles of inflammation, in disease progression and healing, as well as the disadvantages and advantages of inflammation were discussed to drive a more rigorous approach to inflammation. From the discussions, inflammation plays both positive and negative roles in health. Evidently, this study has exposed the good, bad, and ugly of inflammation and proposing therapy for the control of inflammation. At present, Scholars' stance on inflammation is difficult to interpret or understand. On this, further explanations are required.

\section{Compliance with ethical standards}

\section{Acknowledgments}

I wish to thank Emmanuel Anyanwu, of Dandel café, for providing the internet facility.

\section{References}

[1] Medzhitov R. Origin and physiological roles of inflammation. Nature. 2008 July; 454(7203): 428-35.

[2] Ferrero-Miliani L, Nielsen OH, Andersen PS, Girardin SE. Chronic inflammation: Importance of NOD2 and NALP3 in interleukin-1 $\beta$ generation. Clinical and Experimental Immunology. 2007 february; 147(2): 227-235.

[3] Lana, Barhum. 5 Cardinal Signs of Inflammation [Internet]. Verywell; C 2021 [cited 2021 January 5] Available from https://www.verywellhealth.com/signs-of-inflammation-4580526

[4] Takeuchi O, Akira S. Pattern recognition receptors and inflammation. Cell. 2010 Mar 19; 140 (6):805-20.

[5] Ashley NT, Weil ZM, Nelson RJ. Inflammation: Mechanisms, Costs, and Natural Variation. Annual Review of Ecology Evolution Systematics. December 2012; 43: 385-406.

[6] Zhang JM, An J. Cytokines, inflammation, and pain. International Anesthesiology Clinic. June 2007; 45(2): 27-37.

[7] Stiegel MA, Pleil JD, Sobus JR, Madden MC. Inflammatory cytokines and white blood cell counts response to environmental levels of diesel exhaust and ozone inhalation exposures. PLoS ONE. April 2016; 11(4): e0152458.

[8] Noah TA, Zachary MW, Randy JN. Inflammation: Mechanisms, Repair. Wound Practice \& Research. Journal of the Australian Wound Management Association. 2012; 16 (3): 122-129.

[9] Chen L, Deng H, Cui H, Fang J, Zuo Z, Deng J, Li Y, Wang X, Zhao L. Inflammatory responses and inflammationassociated diseases in organs. Oncotarget. January 2018; 9: 7204-7218.

[10] Jeon, S. W, Kim YK. The role of neuroinflammation and neurovascular dysfunction in major depressive disorder. Journal of Inflammatory Research. May 2018; 11: 179-192. 
[11] Thorsten H, Frances B, Toby L. Inflammation and Cancer: A Double-Edged Sword. Cancer Cell. October 2007; 12(4): 300-301.

[12] Van Dyke TE. Cellular and molecular susceptibility determinants for periodontitis. Periodontology 2000, November 2007; 45: 10-13.

[13] Greten FR, Eckmann L, Greten TF, Park JM, Li Z, Egan LJ, Kagnoff MF, Karin M. IKK $\beta$ links inflammation and tumorigenesis in a mouse model of colitis-associated cancer. Cell. August 2004; 118(3): 285-296.

[14] Rakoff-Nahoum S. Why cancer and inflammation? Yale Journal of Biolology and Medicine. December 2006; 79: 123-130.

[15] Murphy SL, Jiaquan BS, Xu MD, Kenneth D, Kochanek MA. Deaths Preliminary Data for 2010. National Vital Statistics Report. January 2012; 1-51.

[16] Singh R, Akhtar N, Haqqi TM. Green tea polyphenol epigallocatechin-3-gallate: inflammation and arthritis. Life Science. June 2010; 86(25-26): 907-918.

[17] Yu-Sheng W, Shiu-Nan C. Apoptotic cell: linkage of inflammation and wound healing, Frontiers in pharmacology. January2014; 5(1) 4.1-7.

[18] Nathan C. Points of control in inflammation. Nature. December 2002; 420: 846-852.

[19] Soehnlein 0, Lindbon L. Phagocyte partnership during the onset and resolution of inflammation. Nature Review, Immunology. June 2010; 10: 427-39.

[20] Fadok VA, Bratton DL, Konowal A, Freed PW, Westcott JY, Henson PM. Macrophages that have ingested apoptotic cells in vitro inhibit proinflammatory cytokine production through autocrine/paracrine mechanisms involving TGF-beta, PGE2, and PAF. Journal of Clinical Investion. February 1998; 101: 890-898.

[21] Freire MO, Van dyke TE. Natural resolution of inflammation. Feriodontology. 2000, August 2013; 63(1): 149 164.

[22] Medzhitov R. Inflammation New adventures of an old flame. Cell. March 2010; 140: 771-776.

[23] Allevena P, Sica A, Solinas G, Porta C, Mantovani A. The inflammatory micro-environment in tumor progression: the role of tumor-associated macrophages. Critical Review in Oncolology/Haematology. April 2008; 66(1): 1-9.

[24] Rao GHR. Integrative Approach to the Management of Cardiometabolic. Journal of Cardiology and Cardiovascular Sciences. July 2018; 2(3): 37-42.

[25] Matzinger P. The danger model: a renewed sense of self. Science. April 2002; 296: 301-305.

[26] Punchard NA, Whelan CJ, Ad cock I. The Journal of Inflammation. Journal of Inflammation. August 2004; 1(1): 1-4.

[27] Maslinska D, Gajewski M, Some aspect of inflammatory process folia. Neuropathologica. January 1998; 36(4): 199- 204.

[28] Martinon F, Mayor A, Tschopp J. The inflammasomes: guardians of the body. Annual Review of Immunology. April 2009; 27: 229-65.

[29] Saraiva M, O'Garra A. The regulation of IL-10 production by immune cells.Nature Review, Immunology. February 2010; 10(3): 170-81.

[30] Ouyang W, Rutz S, Crellin NK, Valdez PA, Hymowitz SG. Regulation and functions of the IL-10 family of cytokines in inflammation and disease. Annual Review of Immunology. April 2011; 29: 71-109.

[31] Rowley AF. The evolution of inflammatory mediators. Mediators of Inflammation. February 1996; 5(1): 3-13.

[32] Tabas I, Glass CK. Anti-inflammatory therapy in chronic disease: challenges and opportunities. Science. 2013 Jan 11;339(6116):166-72.

[33] Weighardt H, Heidecke CD, Emmanuilidis K, Maier S, Bartels H, Siewert JR. et al. Sepsis after major visceral surgery is associated with sustained and interferon-gamma-resistant defects of monocyte cytokine production. Surgery. March 2000; 127: 309-315.

[34] Rajan V, Murray RZ. The Duplicitous Nature of Inflammation in Wound Repair Wound Practice \& Research: Journal of the Australian Wound Management Association. January 2008; 16(3): 122-129. 
[35] Mikkelsen UR, Langberg H, Helmark IC, Skovgaard D, Andersen LL, Kjaer M. ibuprofen and acetaminophen on postexercise muscle protein synthesis. American Journal of Physiology, Endocrinology and Metabolism. 2009; 282(3): E551-556.

[36] Nunes-Silva A. Exercise-Induced Inflammatory Response: To Use or Not use Anti-Inflammatory Medication. Journal of Sports Medicine and Doping Studies. 2014; 4: 142.

[37] Lee KH. Studies on the mechanism of action of salicylate. II. Retardation of wound healing by aspirin. Journal of Pharmaceutical Science. 1968; 57(6): 1042-3.

[38] You HJ, Han SK. Cell therapy for wound healing. Journal of Korean Medical Sciences. 2014; 29(3): 311-319.

[39] Rumalla VK, Borah GL. Cytokines, growth factors, and plastic surgery. Plastic Reconstructive Surgery. 2001; 108: 719-33.

[40] Chazaud B. Inflammation during skeletal muscle regeneration and tissue exercise-induced muscle damage management Immunology and Cell

remodeling: application to Biology. 2016; 94(2): 140-5.

[41] Roberts LA, Raastad T, Markworth JF, Figueiredo VC, Egner IM, Shield A. Cameron-Smith D., Coombes, J. \& Peake J. M. (2015). Post-exercise cold water immersion attenuates acute anabolic signalling and long-term adaptations in muscle to strength training. The Journal of Physiology. 2015; 593(18): 4285-4301.

[42] Isailovic N, Daigo K, Mantovani A, Selmi C. Interleukin-17 and innate immunity in infections and chronic inflammation. Journal of Autoimmunity. 2015; 1-11.

[43] Chiang N, Fredman G, Backhed F, Oh SF, Vickery T, Schmidt BA, Serhan CN. Infection regulates pro-resolving mediators that lower antibiotic requirements. Nature. 2012; 484(7395): 524-528.

[44] Kotas ME, Medzhitov R. Homeostasis, inflammation, and disease susceptibility. Cell. 2015 ; 160 (5): $816-827$.

[45] Irina G, Luzina AD, Keegan NM, Heller GA, W Rook T, Sergei PA. Regulation of inflammation by interleukin-4: a review of "alternatives" Journal of Leukocyte Biology. 2012; 92(4): 753-764.

[46] Muller AK, Meyer M, Werner S. The roles of receptor tyrosine kinases and their ligands in the wound repair process. Seminars in Cell Developmental Biology. 2012; 23: 963-970.

[47] Licastro F, Candore G, Lio D, et al. Innate immunity and inflammation in ageing: a key for understanding agerelated disease. Immunity and Ageing. 2005; 2: 8-21.

[48] Fagiolo U, Cossarizza A, Scala E, Fanales-Belasio E, Ortolani C, Cozzi E, Monti $\quad$ D, Franceschi $\quad C, \quad P a g a n e l l i \quad R$. Increased cytokine production in mononuclear cells of healthy elderly people. European Journal of Immunology. 1993; 23(9): 2375-2378.

[49] Abbatecola AM, Ferrucci L, Grella R, Bandinelli S, Bonafe M, Barbieri M, Corsi AM, Lauretani F, Franceschi C, Paolisso G. Diverse effect of inflammatory markers on insulin resistance and insulin-resistance syndrome in the elderly. Journal of American Geriatrics Society. 2004; 52(3): 399-404.

[50] Peng HB, Rajavashisth TB, Libby P, Liao JK. Nitric oxide inhibits macrophage-colony stimulating factor gene transcription in vascular endothelial cells. Journal of Biological Chemistry. 1995; 270: 17050-17055.

[51] Hotamisligil GS, Shargill NS, Spiegelman BM. Adipose expression of tumor necrosis factor-alpha: direct role in obesity-linked insulin resistance. Science. 1993 Jan 1; 259(5091):87-91.

[52] Sorci G, Faivre B. Inflammation and oxidative stress in vertebrate host-parasite systems. Philosophical Transaction of the Royal Society of London. Series B Biological Science. 2009; 364(1513): 71-83.

[53] Margolis E, Levin BR. The evolution of bacteria-host interactions: virulence and the immune overresponse. In Introduction to the Evolutionary Biology of Bacterial and Fungal Pathogens, ed. F Baquero, C Nombela, G. H Cassell, J, A Guti'errez. 2008; 3-13.

[54] Graham AL, Allen JE, Read AF. Evolutionary causes and consequences of immunopathology. Annual Review Ecology, Evolution, and Systematics. 2005; 36: 373-93.

[55] Kashyap RS, Deshpande PS, Ramteke SR, Panchbhai MS, Purohit HJ, Taori GM, Daginawala HF. Changes in cerebrospinal fluid cytokine expression in tuberculous meningitis patients with treatment. Neuroimmunomodulation. 2010; 17(5): 333-339.

[56] Weil ZM, Norman GJ, Devries AC, Nelson RJ. The injured nervous system: a Darwinian perspective. Progress in Neurobiology. 2008; 86: 48-59. 
[57] Boamponsem AG, Boamponsem LK. The Role of Inflammation in Atherosclerosis. Advances in Applied Science Research. 2011; 4: 194-207.

[58] Libby P. Inflammation in atherosclerosis. Nature. December 2002; 420(6917): 868-874.

[59] Hallenbeck JM, Hansson GK, Becker KJ. Immunology of ischemic vascular disease: plaque to attack. Trends in Immunology. 2005; 26(10): 550-6.

[60] Scott JM, Revesz T. Inflammation in Alzheimer's disease: insights from immunotherapy. Brain. 2013; 136: 26542656.

[61] Stecher B, Denzler R, Maier L, Bernet F, Sanders MJ, et al. Gut inflammation can boost horizontal gene transfer between pathogenic and commensal Enterobacteriaceae. Procedings of National Acadamic of Science. USA. 2012; 109: 1269-74.

[62] Esmerina T, Jean-Jacques M, Dorothee W, Hansjuerg A, Stefano V, Carlo M. Croce Mutator Activity induced by microRNA - 155(miR-155) links inflammation and cancer. Procedings of National Acadamic of Science. 2011; 108(12): 4908-4913.

[63] Mantovani A, Allavena P, Sica A, Balkwill F. Cancer-related inflammation. Nature. 2008; 454: $436-444$.

[64] Colotta F, Allavena P, Sica A, Garlanda C, Mantovani A. Cancer-related inflammation, the seventh hallmark of cancer: links to genetic instability. Carcinogenesis. 2009; 30: 1073-1081.

[65] Schetter AJ, Heegaard NH, Harris CC. Inflammation and cancer: interweaving microRNA, free radical, cytokine and p53 pathways. Carcinogenesis. 2011; 31(1): 37-49.

[66] Curcic S, Holzer M, Frei R, Pasterk L, Schicho R, Heinemann A, Marsche G. Neutrophil effector responses are suppressed by secretory phospholipase A 2 modified HDL. Biochimica et Biophysica Acta (BBA) Molecular and Cell Biology of Lipids. 2009; 1851: 184-193.

[67] Bianchi ME, Manfredi AA. Immunology. Dangers in and out. Science. 2009; 323(5922): 1683-1684.

[68] Gudkov AV, Komarova EA.p53 and the Carcinogenicity of Chronic Inflammation. Cold Spring Harbor Perspective in Medicine. 2016; 6(11): a026161.

[69] Fritsch J, Abreu MT. The Microbiota and the Immune Response: What Is the Chicken and What Is the Egg? Gastrointestinal Endoscopy Clinics North America. 2019; 29(3): 381-393.

[70] Libby P. Inflammatory mechanisms: the molecular basis of inflammation and disease. Nutrition Review. 2007; 65: S140-S146.

[71] Opriessnig T, Giménez-Lirola LG, Halbur PG. Polymicrobial respiratory disease in pigs. Animal Health Research Reviews. 2011; 12: 133-148.

[72] Serhan CN, Brain SD, Buckley CD, Gilroy DW, Haslett C, O'Neill LA, Perretti M, Rossi AG, Wallace JL. Resolution of inflammation: state of the art, definitions and terms. Federation of American Societies for experimental Biology Journal. 2007; 21: 325-332.

[73] Zhou Y, Hong Y, Huang H. Triptolide Attenuates Inflammatory Response in Membranous Glomerulo-Nephritis Rat via Downregulation of NF-KB Signaling Pathway. Kidney and Blood Pressure Research. 2016; .41: 901-910.

[74] Libby P, Ridker PM. Hansson GK. Progress and challenges in translating the biology of atherosclerosis. Nature. 2011; 473(7347): 317-325.

[75] Back M, Yurdagul A, Jr Tabas I, Oorni K, Kovanen PT. Inflammation and its resolution in atherosclerosis: mediators and therapeutic opportunities. Nature Reviews, Cardiology. 2019; 16(7): 389-406.

[76] Hansson GK, Robertson AK, Söderberg-Nauclér C. Inflammation and atherosclerosis. Annual Review of Pathology. 2006; 1: 297-329.

[77] Tabas, I. Macrophage death and defective inflammation resolution in atherosclerosis. Nature Review, Immunology. January 2010; 10:36-46.

[78] Ross AC. Relationship between Inflammatory Markers, Endothelial Activation Markers, and Carotid Intima-Media Thickness in HIV-Infected Patients Receiving Antiretroviral Therapy.Clinical Infectious Disease. 2009; 49: 1119-1127. 
[79] Roxvall L, Sennerby L, Heideman M. Anti-inflammatory agents inhibit leukocyte accumulation and vascular leakage induced by trypsin and trypsin-digested serum in hamster cheek pouch. Journal of Surgical Research. 1993; 54: 207-11.

[80] Roxvall L, Sennerby L, Johansson BR, Heideman, M. Trypsin-induced vascular permeability and leukocyte accumulation in hamster cheek pouch: The role of complement activation. Journal of Surgical Research. 1990; 49: 504-13.

[81] Weiner M, Piliero SJ. Nonsteroidal anti-inflammatory agents. Annual Review of Pharmacology. April1970; 10: 171-198.

\section{Author's short Biography}

NWACHUKWU Francis C. is a holder of Ph. D. in Biochemistry with a specialty in Traditional
Medicine. He is a versatile lecturer with research experience of over 10 years in a tertiary
institution. His research contributions in Biomedical Sciences have positioned him amongst the
editors and reviewers of reputable Journals both National and International. His research
works has been cited by different scholars. His contemporaries see him as an erudite scholar.

